\title{
Introduction
}

For decades, there has been an insistence that the world needs women leaders. Although progress has been made, across the globe the number of women in senior leadership positions in business, government and nonprofit sectors remains disproportionately low. This collection of essays presents the stories of successful women leaders in India, Japan, Jordan and the United Kingdom.

The slow progress of women's advancement was repeatedly noted in many of the reports that were issued in 2015 to mark both the twentieth anniversary of the Beijing Platform for Action (BPfA) and the deadline for achieving the Millennium Development Goals (MDGs), many of which focused on women's empowerment. The research findings point to mixed results of achieving that empowerment.

One of the high points is the increasing number of girls being educated, more than ever before. However, there is little evidence that successes on the educational front translate into successes in addressing the gender gap in workplace participation in general or, more particularly, in increasing the number of women in the ranks of the most senior leaders in major global organizations. In the 20 years since BPfA, 'the chances for women to participate in the labour market remain almost 27 percentage points lower than those for men' (Debusscher, 2015). In addition, there has been little change in sectoral and occupational segregation and a persistent gender wage gap. International Labour Organization (ILO) reports indicate a bit of progress in women's advancement through the 'glass ceiling' with some women even being appointed to C-suite and/or board positions. Overall, however, "while women have advanced in business and management, they continue to be shut out of higher level economic decision-making despite activism in the last decade to smash the "glass ceiling"" (ILO, 2015). The progress of women is described as 'glacial.' 
In its 2016 report surveying 36 countries, Grant Thornton International found on average women hold 24 percent of senior positions in business. This is a return to a previous high from a downturn in 2015. However, the number of firms in which there are no women in senior positions remains unchanged at 33 percent. Eastern European and Asian countries continue to top the list of countries with women in senior leadership positions at 35 percent and 34 percent respectively; Russia leads with 45 percent and is followed by Lithuania and the Philippines both at 39 percent. It is interesting to note that in Eastern Europe the rate is attributed to the old communist 'maxim that men and women are equal partners [which] seems to have sparked a trend within the business world that shows little sign of diminishing' (Grant Thornton International Ltd., 2016). The five ASEAN countries included in the Grant Thornton study all rank above the global average in terms of the number of women who are in senior leadership positions. This is attributed in part to social and governmental support for women's education, with large numbers of women completing degrees at both the undergraduate and graduate level, sometimes in larger numbers than men.

The findings are less promising when it comes to Japan, India, the United Kingdom and Jordan, the four countries in which the women in this study work. These countries have consistently been below the global average when it comes to the number of women in senior management positions. Japan at 7 percent is at the bottom of the list; India at 16 percent and the United Kingdom at 21 percent are in the bottom third (Grant Thornton, 2016). Jordan, a country not included in the Grant Thornton study, ties the United Kingdom at 21 percent according to data prepared by the International Finance Corporation (2015).

\section{WOMEN AND LEADERSHIP}

One of the most controversial issues in studying women leaders is the question: Do women lead differently? In order to explore that question, in the section below we briefly outline some traditional theories of leadership. This will be useful in considering whether one can distinguish certain qualities that differentiate women leaders 
from their male counterparts. This discussion will also provide a lens through which to consider the women leaders featured in this volume.

\section{Are Men and Women Different?}

There is literature that argues that there are certain traits, presumably inherited traits, which distinguish leaders from the rest of us. According to this theory, leaders are born with these character traits. These vary in the literature, but the most commonly cited innate traits are intelligence, self-confidence, determination or drive to succeed, integrity and sociability (Shriberg and Shriberg, 2011). Some theorists add charisma to the list (Conger and Kanungo, 1998). Being tall has also been cited as an important trait of leadership although there is only weak evidence that this is important.

If trait theory has any validity, then do women have genetically different leadership traits than men? Whether or not such so-called traits are genetic has never been proven, and it is difficult at best to identify leaders by these traits when they are children or young adults. Of course, one can socially construct and reinterpret these qualities of leadership after the fact when they have become leaders through appealing to these so-called traits as descriptive of certain leaders.

The issue remains, however, as to whether and in what ways men are different from women and how those differences might affect their leadership styles. Early in the twentieth century none other than Sigmund Freud argued, 'I cannot evade the notion ... that for women the level of what is ethically normal is different from what it is in men' (Freud, 1925; 1961, 257, re-quoted in Gilligan, 1977 in Ciulla et al., 2013, volume 2, 286).

One distinguished contemporary thinker, Carol Gilligan, argues that there are vast differences between men and women. Whether or not these are genetic traits is a question Gilligan does not consider. Rather, she argues that 'the feminine experience and construction of social reality [is in a] distinctive voice, recognizable in the different perspective [the voice] brings to bear on the construction and resolution of moral problems' (Gilligan, 1997 in Ciulla et al., 2013, volume 2, 286). In other words, women perceive and frame their experiences using socially constructed mindsets or mental models 
that are distinctive for women. Gilligan argues that women are less individualistic and less self-absorbed than men, are extremely concerned about their relationships with others, contextualize rather than generalize moral problems, make moral judgments that are situational rather than universal, and exhibit a model of leadership that is collaborative rather than hierarchically focused. Gilligan backs up these contentions with a series of empirical studies of women decision-makers who seem to demonstrate the validity of her claims. For example, Gilligan found that most women identify morality as situational, but she also found an overall consensus that inflicting gratuitous harm on other people is almost always wrong. A feeling of the value and moral importance of empathy and fellow feeling usually overrode questions of fairness or justice. Women also worried about their own sense of self-identity and whether they were respected as independent individuals with the capacity to make their own decisions. Taking responsibility for their choices was not an issue, but women often worried about whether they were taken seriously by others, particularly men, as morally equal beings. She found:

Women impose a distinctive construction on moral problems ... The development of women's moral judgment appears to proceed from an initial concern with survival, to a focus on goodness, [identified primarily as avoiding harm to others,] and finally to a principled understanding of nonviolence as the most adequate guide to the just resolution of moral conflicts (Gilligan, 1977 in Ciulla et al., 2013, volume 2, 304).

If Gilligan is even partly correct, then women leaders will socially construct reality differently than men, being less egoistical, more relationship focused, and more collaborative as leaders than their male counterparts. Such generalizations are not absolute, and many men also exhibit these allegedly female leadership characteristics. Alternately, women as a gendered group might also socially construct their ideas of leadership from a masculine point of view, and some do. What we can conclude is that how a person constructs a definition of leadership frames her own leadership style and the ways in which she interprets the leadership capabilities of others. 


\section{Leadership Styles}

Carol Gilligan's studies were conducted in the 1970s. Nevertheless, they set up a stereotype for women and women leaders that exists in the literature today. This stereotype, recently evidenced in another study of American women leaders (Werhane et al., 2007), found that women leaders are more likely than men to be transformational leaders. A transformational leader is a leader who sees her role as inspiring her followers and her organization with a set of goals or a vision, goals that together the organization and its constituents all agree to and contribute to achieving those ends (Bass, 1998; Burns, 2003). It is not a top-down hierarchical model because rather than ordering the pursuit of goals or vision, the leader convinces and inspires followers thereby bringing them along in pursuit of shared goals or visions.

According to this same study, women were less likely to emulate a model of a transactional leader. A transactional leader is a person who, because of her position, has authority over others, sees herself in charge and views leader-follower relationships as transactions between performance and reward rather than forms of interpersonal relationships. As the studies found, this hierarchical model, still evidenced in many organizations, is often rejected by women in positions of power. Rather, women leaders more often see themselves as partners with their followers wherein the leader functions as an inspirational model, mentor and collaborator. Leaders in this transformational model interact with their followers not as 'bosses' but as team leaders and coaches bringing along their mentees to produce results for the organization (Werhane et al., 2007).

Judith Rosener describes this kind of leadership as 'interactive leadership' that entails shared power and information as well as energizing their employees to believe in the value of their contributions and to participate in the organizational decision-making processes. While recognizing that men, too, can and often do engage in interactive leadership, she finds this kind of leadership more prevalent in women executives (Rosener, 1990).

Transformational leaders are usually great communicators with others in their organization, and they do not fear hiring or encouraging managers who could replace them. As Robin Eagly writes: 
In this tradition, transformational leadership involves establishing oneself as a role model by gaining followers' trust and confidence. Such leaders delineate organizations' goals, develop plans to achieve those goals, and creatively innovate, even in organizations that are already successful. Transformational leaders mentor and empower their subordinates and encourage them to develop their potential and thus to contribute more effectively to their organization (Eagly, 2007, 2).

Eagly identifies this style of leadership as 'important to leadership, certainly in some contexts and perhaps increasingly in contemporary organizations ...' (Eagly, 2007, 2; see also, Rosener, 1990; Eisner, 2013).

James MacGregor Burns, one of the founders along with Bernard Bass of the idea of transformational leadership, creates a third category, 'transforming leadership.' A transforming leader is a person who has a moral vision and seeks to transform her followers to help realize this end. Gandhi, for example, was such a leader (Burns, 1998). We shall present some examples of such leaders in the narratives that follow.

Being a feminine transformational leader is sometimes characterized as 'soft' with those qualities of collaboration and consensus sometimes viewed as less effective than an aggressive, take charge, 'strong' style that is often stereotyped as male. In a male-dominated hierarchical organization it may be challenging for a woman to become a leader without changing her way of leading. But women who adopt such aggressive styles of leadership are often caricatured as too bossy, too aggressive and/or too rigid (Eagly, 2007, 6; see also, Eagly and Johannesen-Schmidt, 2001, 787 and Jamieson, 2010, 37).

They [women] are expected to be communal because of the expectations inherent in the female gender role, and they are also expected to be agentic because of the expectations inherent in most leader roles. However, because agentic displays of confidence and assertion can appear incompatible with being communal, women are vulnerable to becoming targets of prejudice. Sometimes people view women as lacking the stereotypical directive and assertive qualities of good leaders - that is, as not being tough enough or not taking charge (Eagly, 2007, 4). 


\section{Does Gender Make a Difference?}

In an article on current leadership styles Susan Eisner reports on leadership styles and gender based on her analysis of interviews published in the Sunday New York Times 'Corner Office' series (2013). Eisner found that women focus more on people and relationships than on tasks and results. Women were better at encouraging others and valuing others' worth as individuals. However, many men, too, were good at sharing power and influence, characteristics often attributed to women. None of the women indicated any interest in transactional leadership. Both women and men valued what they called 'authentic leadership' describing such leaders as 'frank, consistent, dependable, self-efficacious, optimistic, resilient [people who] walk the talk' (Eisner, 2013, 30). Referencing Schermerhorn et al. (2010), Eisner notes that leaders orientated toward their followers are often 'engaged in a reciprocal sharing of influence with followers with whom a common vision and goals are then enthusiastically achieved as a result of that partnering' $(2013,30)$. Both women and men mentioned but did not wholeheartedly adopt a servant-leadership orientation, often understood as leaders who 'are value-driven, seek to affect employees and community positively, listen, earn and keep stakeholder trust, and advance the interest of others before self' $(2013,30)$. This mild endorsement might have been because the word 'servant' conveys servitude, although the original author of this concept, Robert Greenleaf, was not thinking in those terms. Rather, Greenleaf was trying to emphasize that a leader has obligations, important obligations, to those to whom the leader is responsible, thus it is the leader who is the 'servant' to her managers, employees and workers (Greenleaf, 1977, 2002).

Both men and women were committed to a transformational style of leadership, indicated the importance of mentoring and acknowledged a change in their leadership style. For women the predominant changes in style centered on more effective communications, acquiring a more professional manner and becoming less rigid or bossy. The two latter changes appear to be related to overcoming gender-based perceptions of women leaders and are reflected in Eisner's finding that 'almost one-third of the women commented that gender affected development and career' $(2013,31)$. In addition to the impact of gender, other attributes that Eisner found are 
associated with women include a transformational approach to leadership and a concern for enhancing others' self-worth (2013, 34-5).

Eisner concluded that men and women were more alike than previous studies indicate. Both emphasized consensus building, a transformational style, mentorship and a focus on balancing work/ life agendas. Both were more concerned with situationally based flexible leadership.

In summary, according to Eisner, as well as other writers including Sweeney (2011) and Greenberg and Sweeney (2005a, 2005b), while men and women work on developing similar leadership styles, it is possible to identify some differences in the manner and motivation for doing so. Both work on being listeners to their constituents; however, 'women leaders are not just listening to form an answer, but really listening, learning, reflecting, then implementing a plan that incorporates the best of everyone's ideas' (Greenberg and Sweeney, 2005b, 35). Likewise, both are concerned with results that, among other qualities, require commitment, determination, and persuasiveness. Women's approach, however, is distinct. Their 'strong people skills ... and willingness to see all sides enhances their persuasive ability' (Greenberg and Sweeney, 2005b, 34). Greenberg and Sweeney believe there is evidence pointing to a new leadership style that women are creating. Citing Jeannette Lichner who claims, 'The female view that we strengthen ourselves by strengthening others is re-defining leadership,' Greenberg and Sweeney note that women leaders 'are assertive, persuasive, empathic, willing to take risks, outgoing, flexible and have a need to get things done' $(2005 \mathrm{~b}, 36)$. They conclude that such 'personality qualities combine to create a leadership profile that, one could easily argue, is much more conducive to today's diverse workplace, where information is shared freely, collaboration is vital and teamwork distinguishes the best companies' (2005b, 36).

\section{Challenges for Women}

A recent 2014 study conducted by the Caliper Corporation, a talent management company engaged in leadership development and organizational change, showed that women focus more on people and relationships than on tasks and results. Women were better at encouraging others and valuing their worth as individuals. The 
Caliper study also outlined 'five barriers that caused the highest negative impact' for women in organizations. These were:

- Feelings of guilt for not spending enough time with family because of work.

- Family responsibilities interfering with work.

- Resistance from other current leaders.

- Having to outperform male leaders to be considered effective.

- Lack of support in the household when work is demanding (Caliper Research \& Development Department, 2014, 5).

Women who see these as barriers are more likely to react negatively to a stereotypical threat. And these women tended to react negatively to transactional forms of leadership even though at work they may be copying a masculine style to avoid being stereotyped as a 'soft' female.

\section{Systems Thinking and Global Leadership}

The women we feature in this book are global leaders. While each is physically located in a particular country, their organizations are global organizations. As Nancy Adler once put it, 'Global leaders, unlike domestic leaders, address people worldwide ... A fundamental distinction is that global leadership is neither domestic nor multidomestic: it focuses on cross-cultural interaction' (Adler, 1997, 175; re-quoted in Werhane in Ciulla et al., 2013, volume 3, 16). Moreover, and this is a point that is seldom made in the leadership literature, global leaders must think systemically. A system - whether it is an organization, nation or culture - is a humanly created system. Since human beings are themselves adaptable, all human systems are interactive, dynamic, adaptive and always in a process of change. Together the relationships in such systems are 'the complex interactive dynamic that is productive of adaptive outcomes' (Uhl-Bien et al., 2007, 119). These are often called 'complex adaptive systems.'

The idea that the world is a macro complex adaptive system is not a new one. A good historian will point out that these interrelationships have existed at least since the early explorers and traders. The twenty-first century difference is that the Internet, media, ease 
of communication and global trading have made these relationships transparent and unavoidable (Friedman, 2007).

A hierarchical transactional leader, proponents of systems thinking argue, does not fit with the complexity of the twenty-first century global macro system where almost every activity is transparent, media discoverable and related in some way or another to every other activity (Friedman, 2007; Uhl-Bien et al., 2007; Collier and Esteban, 2000, the latter two reprinted in Ciulla et al., 2013). This is not merely because of the complex interactions and constant exchanges of data, goods and services. A hierarchical leadership model does not work well in this century because entrepreneurs, managers and executives are themselves constantly adapting to these processes and flux. Thus merely to give or take orders is a detriment to agile, flexible creative thinking that is necessary for success in this environment.

A systems approach to leadership concentrates on the processes of systemic leadership rather than the individual leader. This is because the leader herself is embedded in an organization that itself is part of a global complex system. In this complex global political economy, innovation, adaptability and creativity as well as collaboration are essential components of a successful leader. Werhane and Painter-Morland have not only argued that these characteristics are by and large characteristics of women leaders, but also have gone so far as to conclude that women are or can be more successful global leaders than men because of the demands of operating in such a complex environment (Werhane, 2007; Painter-Morland, 2011). Global leaders, then, according to Adler, should emulate what Gilligan and others have characterized as a feminist style. The women we have included in this book illustrate successful adaptations of this style of leadership.

\section{CONCLUSION}

Although leadership styles are steadily morphing into each other, there is still strong evidence that the approaches to leadership of women and men are different. This is often because each socially constructs his or her experiences and concepts of reality in different ways. These socially constructed views of leadership are probably not genetically ingrained, because we see a great deal of evidence 
that some men as well as a majority of women approach the world as engaged situational leaders who are involved in collaborative enterprises. We also find women leaders who emulate the hierarchical aggressive style often attributed to men. Moreover, what we learned from the Caliper study is that both men and women leaders are becoming more like transformational leaders. In a global world of overlapping complex adaptive systems this form of leadership transformational and collaborative, with a preoccupation with networking rather than directing - is critical if global change is possible and if enterprises and governments are to survive and thrive in this century.

The ideal of leadership may be the aspiration that 'Good leadership is not male or female; it is simply good leadership' (Beasley, 2005 , 92). Our research indicates that we are very far from achieving this ideal despite the stories of the women featured in this book that demonstrate there are women who are extremely good leaders. 
Regina Wentzel Wolfe and Patricia H. Werhane - 9781785368714 Downloaded from PubFactory at 04/26/2023 10:02:21AM 